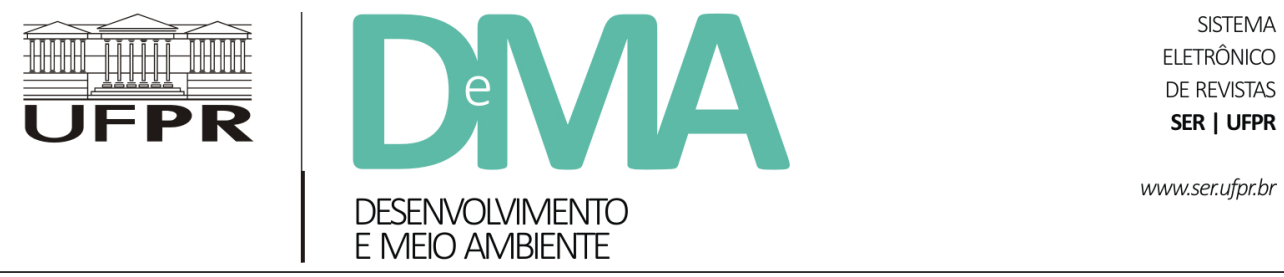

\title{
Identidades de pescadores caiçaras: heroísmo e precariedade em populações tradicionais?
}

\section{Caiçaras Fishermen Identities: Heroism and Precariousness in Traditional Populations?}

\author{
Nancy Ramacciotti de OLIVEIRA-MONTEIRO ${ }^{1 *}$, Rodolfo Eduardo SCACHETTI ${ }^{1}$, Victor NAGIB ${ }^{1}$ \\ ${ }^{1}$ Universidade Federal de São Paulo (UNIFESP), Santos, SP, Brasil. \\ *E-mail de contato: nancy.ramacciotti@unifesp.br
}

Artigo recebido em 31 de agosto de 2016, versão final aceita em 23 de maio de 2017.

RESUMO: Numa perspectiva eriksoniana, a identidade psicossocial manifesta-se no cotidiano ocupacional, familiar e intersocial. Transformações trazidas pelas interações ecossistêmicas que envolvem natureza, sociedades e tecnologia ocorrem, em ritmos e abrangências peculiares, nas diferentes áreas de trabalho humano da contemporaneidade. Dados da literatura mostram a pesca artesanal impactada por essas transformações. Com o objetivo de estudar aspectos de identidade em perfis psicossociais de pescadores artesanais, foram investigados três pescadores caiçaras da Baixada Santista (SP) através de entrevistas abertas, questionários e observações participantes. Com metodologia qualitativa, os resultados foram sistematizados indicando enaltecimento da profissão/ofício (o pescador herói que enfrenta grandes desafios da natureza) e atributos de um trabalhador envolvido em precariedades (prejuízos à saúde e subsistência), com poucos recursos de educação formal e de poder para enfrentamento de desafios emergentes das interações políticas contemporâneas. Os dados foram discutidos em perspectivas controversas do entendimento sobre comunidades de pescadores artesanais como populações tradicionais, em sua convivência com processos de modernização próprios da cultura urbana.

Palavras-chave: pesca artesanal; comunidades caiçaras; pescadores; Baixada Santista.

ABSTRACT: From an Eriksonian perspective, psychosocial identity manifests itself in everyday occupational, family and intersocial relations. Changes resulting from ecosystemical interactions involving nature, society and technology take place in peculiar rhythms and ranges, in different areas of contemporary human work. Research shows artisanal fishing is impacted by these changes. In order to study aspects of identity in the psychosocial profiles of artisanal fishermen, three caiçaras fishermen from Baixada Santista (SP) were investigated through open interviews, questionnaires and participant observation. Using qualitative methodology, the results were systematized indicating enhancement of the profession / craft (the hero fisherman that faces major challenges from nature) and attributes of a worker involved in precariousness (harm to health and livelihood), with few resources from formal education and power to face the emerging challenges of contemporary political 
interactions. The data was discussed in controversial perspectives of understanding on the artisanal fishermen communities as traditional populations, in their coexistence with the modernization processes of urban culture.

Keywords: artisanal fishing; caiçaras communities; fishermen; Baixada Santista.

\section{Introdução}

As sociedades e a natureza interagem num ecossistema vivo e em constante transformação. Essas interações ecológicas ocorrem, através do tempo, em rede de diversos sistemas, integrando, por exemplo, elementos da industrialização, da tecnologia e da natureza (Di Felice et al., 2012). Em todas as formas de sociedade, tais interações promovem transformações e também transições, ainda que em dimensões particulares e em ritmos diversos. No caso de comunidades tradicionais, essas alterações são mais lentas se comparadas a organizações sociais mais permeáveis a processos de modernização da cultura urbana ocidental.

Possuindo forte sentido de pertinência familiar, seja com a família nuclear como com parentes, em relações de compadrio, as comunidades tradicionais são tidas em sua forte dependência dos recursos naturais e por uma estrutura simbólica delineada por condições de certo isolamento, tanto nos seus territórios físicos como em suas relações sociais. Tais populações denotam ligação peculiar com o espaço que ocupam, no qual o grupo se reproduz econômica e socialmente, com tendência à ocupação de territórios por várias gerações, a despeito de deslocamentos de alguns de seus membros. Comparados a outros grupos urbanos, os agrupamentos de comunidades tradicionais mostram reduzida acumulação de capital e fraco poder político. Além disso, as comunidades tradicionais dão grande importância a mitos e rituais associados às suas atividades de sobrevivência, possuindo grande identificação de pertencimento a uma cultura que é distinta de outras. Um de seus atributos característicos é a reprodução de seus modos de vida, por intermédio de elementos de cooperação social e de especificidades nas relações com a natureza, que tendem a ser particulares e de manejo sustentado do meio ambiente (Diegues, 2000).

Tidas como comunidades tradicionais, por grande parte da literatura, as comunidades de pescadores artesanais brasileiras, a partir das décadas de 1930 a 1950, passaram a constituir uma identidade caracteristicamente associada ao mundo marítimo, deixando de serem comunidades de lavradores-pescadores (Adams, 2000a).

Muitas populações pescadoras artesanais do litoral brasileiro são chamadas de "caiçaras". O termo "caiçara" deriva do tupi-guarani ("caá-içara"), uma maneira como os indígenas denominavam as estacas colocadas em torno das tabas para captura de peixe (Diegues, 1988). Dentre as inúmeras culturas litorâneas regionais ligadas à pesca, o termo caiçara é a denominação para as comunidades de pescadores encontradas no litoral dos estados de Rio de Janeiro, São Paulo e Paraná (Diegues, 1999). Para Romani (2011), essas comunidades que reclamam para si o nome de "caiçaras" mantém costumes produtivos, artísticos e alimentares próprios, manifestando relação de grande interdependência e vínculo com os espaços habitados.

Desde o início do século XX, as comunidades caiçaras são objeto de interesse histórico, geográfico e antropológico. No litoral paulista, há estudos datados da década de 1940 sobre pescadores e comuni- 
dades caiçaras de Iguape, Cananéia, Ilha Comprida, São Sebastião e Ilha Bela (Diegues, 2000). Investigações contemporâneas sobre a pesca de caiçaras encontram-se em publicações mais voltadas para transformações vinculadas a conflitos sociais e ambientais que perpassam essas comunidades. Ao se tratar de pescadores artesanais da Baixada Santista, por exemplo, Moreira (2010) e Vale (2011), ao lado da análise da qualidade e produtividade da pesca artesanal, e o uso de recursos pesqueiros, apontam impactos no cotidiano e na qualidade de vida dos caiçaras a partir da influência de vetores socioculturais internos (como doenças, mortes e mudanças de residência) e externos (como as transformações sociopolíticas e naturais, nas épocas de alterações econômicas e/ou de defeso).

Por sua vez, estudos sobre a cultura caiçara, como aqueles voltados para condições de ascendência e descendência, ocupação de territórios, outros meios de subsistência, aspectos religiosos, música e danças, trazem referências da inter-relação das comunidades caiçaras com produtos e processos da cultura urbana ocidental, como pode ser encontrado em Diegues (1999), Adams (2000a; 2002), Freitas \& Seixas (2011).

Todas essas contribuições, de forma mais ou menos direta, apontam que elementos da modernidade e da globalização trouxeram diversos impactos e desafios para a pesca artesanal. Em Adams (2000b), por exemplo, encontram-se considerações sobre o papel transformador da chegada do barco a motor e da pesca embarcada a essas comunidades, culminando com a redução, ou mesmo a eliminação, de atividades agrícolas que os pescadores praticavam o que, para a autora, constituiu um elemento fundamental para passagem de um dos ciclos econômicos que esses pescadores teriam vivido. $\mathrm{O}$ estudo de Romani (2011), por sua vez, apresentou uma análise histórica de conflitos ambientais relativos a pescadores artesanais da Baixada Santista (SP), com extensa descrição de lutas de caiçaras por suas terras, entraves para sua posse legal, e vantagens que os grandes empreendimentos imobiliários possuíam nessa disputa. Também Moreira (2010), no estudo de quatro comunidades tradicionais de pescadores da Baixada Santista (SP), descreveu a condição de conflitos sociais e ambientais que permeavam essa região.

$\mathrm{O}$ incremento de atividades portuárias no porto de Santos e o aumento de atividades industriais em áreas vizinhas a comunidades tradicionais do litoral da Baixada Santista (SP) são tidos como causas de impactos negativos para a pesca artesanal, causando o afugentamento de peixes e o aumento da poluição hídrica na região (Nagib, 2014). O crescimento urbano, associado à especulação imobiliária, ainda teria provocado a migração de moradores de várias comunidades tradicionais de pescadores, de praias como a de Guaiuba e das Astúrias, no município de Guarujá (SP) (Nagib, 2014), e de Toque-toque, no município de São Sebastião (SP) (Noffs, 2006).

Nessa linha de impactos negativos que atingem comunidades de pescadores artesanais, trabalhos sobre a comunidade da Ilha Diana, em Santos (SP), realizados por Stori et al. (2012), trazem análises de transformações e de declínio da pesca paralelos à expansão portuária, e a construção do complexo portuário na Ilha Barnabé, vizinha à Ilha Diana. Não só aspectos negativos foram colocados por esses estudiosos, que também salientaram elementos de adaptabilidade e resiliência no sistema socioecológico daquela comunidade. Ainda nesse sentido, o de positividade nas interações com elementos não, ou pouco, tradicionais, Moreira et al. (2009), 
em estudo sobre a exploração dos manguezais da Baixada Santista, igualmente mostraram aspectos de diversidade e de versatilidade dos pescadores caiçaras ante a grandes conflitos socioambientais.

Em dimensão de outra natureza, encontram-se pesquisas sobre a saúde de pescadores, sendo a atividade de pesca artesanal em água salgada considerada com permeações de riscos graves para saúde (Brasil, 1999). Os pescadores artesanais estão sujeitos às intempéries e a agentes patológicos, que acarretam acidentes e problemas de saúde (Rosa \& Mattos, 2010), como doenças pulmonares (Brasil, 2009; Rios et al., 2014), perdas auditivas (Rocha, 2013; Rios et al., 2014), problemas musculares e nas articulações (Rocha, 2013; Silva, 2013; Rios et al., 2014), doenças relacionadas ao consumo de bebidas alcoólicas (Brasil, 2009; Lira, 2010; Bezerra et al., 2011; Rios et al., 2014), além de patologias associadas à intensa e prolongada exposição ao sol (Bezerra et al., 2011; Pena et al., 2013; Rios et al., 2014). Essas condições patológicas podem ser agravadas quando o produto da pesca se torna escasso, ou menos rentável, ficando o pescador por mais tempo exposto aos fatores de risco associados à sua profissão.

Não obstante a riqueza e diversidade de estudos sobre caiçaras, como anteriormente apresentadas, a perspectiva de investigação de elementos psicossociais e de identidade desses pescadores ainda pode encontrar espaços de agregação nas pesquisas sobre o tema. A proposta deste artigo é contribuir com o escopo desses trabalhos apresentando elementos identitários de pescadores caiçaras (de cotidiano ocupacional, familiar e interpessoal), para posteriormente discuti-los num pano de fundo de reflexões sobre comunidades tradicionais.

Foi Erikson (1998) o primeiro estudioso a voltar-se, em meados do século XX, aos estudos do desenvolvimento da identidade, que ocorre em todas as idades da vida, da infância até a velhice. Segundo a perspectiva psicossocial eriksoniana, a identidade abarca aspectos interpessoais e ideológicos, abrangendo áreas como valores, amizades, relacionamentos amorosos, atividades cotidianas, também de lazer e de tempo livre, aspectos profissionais e ocupacionais, política, religião e filosofia de vida.

A partir dessas proposituras, este artigo vai apresentar uma pesquisa empírica que teve por objetivo realizar um levantamento de perfis identitários de pescadores artesanais caiçaras que habitavam territórios próximos a um grande centro urbano. Para tanto, foram acompanhados e estudados seus cotidianos na rotina pesqueira e na relação com a família e o entorno da comunidade, seus pontos de vista sobre si mesmos enquanto pescadores artesanais, suas percepções acerca de transformações nas comunidades caiçaras em que viviam (muito próximas a regiões metropolitanas), além de aspectos relativos à saúde e doença, condições econômicas e de escolaridade, e também lazer. O estudo pretendeu reconhecer fronteiras nos perfis psicossociais desses pescadores, em busca de referências identificatórias de pessoas de comunidades caiçaras em processos contemporâneos de interações sociotécnicas e ambientais, e confrontá-las com reflexões controversas pertinentes a características de comunidades consideradas tradicionais.

\section{Método}

O desenho metodológico da pesquisa foi de natureza qualitativa, com realização de entrevistas 
abertas em um modelo de Rodrigues (1978), seguidas de questionários (incluindo o Teste de Identificação de Distúrbio de Uso do Álcool [AUDIT, do inglês Alcohol Use Disorder Identification Test]) ${ }^{1}$, do Critério de Classificação Socioeconômica Brasil (Associação Brasileira de Empresas de Pesquisa, 2016), e de observações participantes com três pescadores artesanais da Baixada Santista (SP), que serão adiante referidos com os nomes fictícios de Tomé, Pedro e Thiago. Esses participantes foram selecionados por critérios de conveniência e de acessibilidade, além do preenchimento das condições: ter mais de 30 anos de exercício da pesca artesanal, conhecer e praticar pelo menos dois métodos distintos de pescaria artesanal, possuir meio de transporte aquaviário (barco e/ou canoa) e exercer atividades de pesca por pelo menos três vezes por semana.

A investigação seguiu preceitos éticos de pesquisa com seres humanos, tendo o projeto recebido aprovação do Comitê de Ética em Pesquisa (CEP/ UNIFESP). Os dados foram coletados nos contextos ambientais cotidianos dos pescadores, o que permitiu validade ecológica para o estudo. Entre 2014 e 2015, foram feitas 19 visitas ao campo, nas quais houve de três a quatro encontros com cada participante para realização de entrevistas abertas (com duração aproximada de 40 minutos) e entrevistas com roteiro/questionários (com duração em torno de 30 minutos). Para levantamento da vida cotidiana, atividades pertinentes à pesca artesanal e interações socioambientais, foram realizadas sessões de observação participante, com utilização de diário de campo. Essas observações duraram um período de aproximadamente 14 horas, incluindo saídas para pesca, para atividades de comercialização do pescado e para visitas às suas residências.

O material das entrevistas abertas, um total de cerca de três horas e meia de gravação, foi digitalizado. Em conjunto com as respostas aos questionários, os dados sofreram tratamento qualitativo com parâmetros de análise de conteúdo (Bardin, 2009), havendo leituras e releituras para levantamento dos dados emergentes que foram conjugados com os objetivos do estudo e também com elementos da literatura pertinente. Assim, com esse procedimento de análise, foram levantados dados de cotidiano identitário, manifestações sobre transformações nas atividades de pesca, aspectos relativos à saúde e doença, além de referências a medos e inseguranças, e também valores.

A Figura 1 mostra os lugares em que ocorreu o levantamento dos dados: no estuário de Santos e de Guarujá, às margens de praia arenosa. Esses locais ficam na Baixada Santista, região metropolitana do litoral do estado de São Paulo, que abarca nove municípios (Santos, Guarujá, Bertioga, São Vicente, Cubatão, Praia Grande, Mongaguá, Itanhaém e Peruíbe). A menos de $100 \mathrm{~km}$ de distância da cidade de São Paulo e da região industrial do $\mathrm{ABC}$, a Baixada Santista é densamente povoada; apesar de ocupar apenas $1 \%$ do território paulista, é a segunda região do Estado em densidade demográfica. A partir dos anos de 1970, houve grande desenvolvimento da indústria, do comércio, do turismo, e de construções urbanas nessa região metropolitana. O Porto de Santos é o mais importante complexo portuário da América do Sul, pelo qual escoa o maior volume da produção brasileira. $\mathrm{O}$ canal do estuário desse

\footnotetext{
${ }^{1}$ Desenvolvido pela Organização Mundial de Saúde (OMS) no final da década de 1980, o AUDIT é um instrumento que detecta o consumo de álcool. Segundo Santos et al. (2012), é uma das medidas mais utilizadas para identificação e rastreamento do uso abusivo de álcool.
} 
porto, o maior da América Latina, sempre recebeu intervenções de dragagem, mas um aprofundamento maior desse canal (de 12 para 15 metros) foi implantado a partir de 2008, aumentando a movimentação de cargas, principalmente por permitir que embarcações de maior porte atracassem no porto, os chamados navios Pós-Panamax.

\section{Resultados}

Tendo em vista que o objetivo principal desta pesquisa foi o de traçar perfis psicossociais identitários de pescadores artesanais caiçaras, a forma escolhida para apresentar os resultados foi uma exposição de "retratos" psicossociais dos três
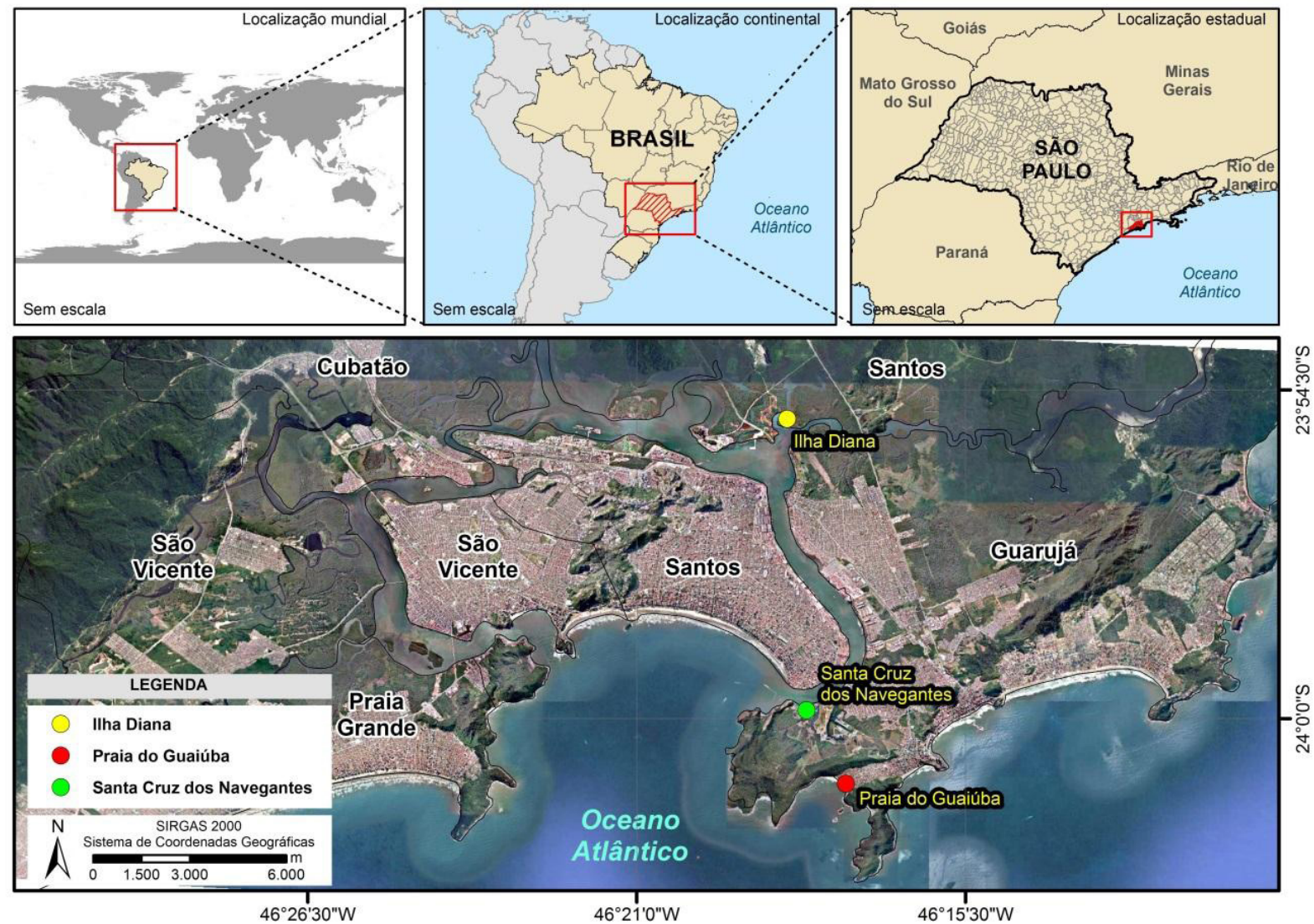

FIGURA 1 - Localização geográfica dos bairros em que residiam os três participantes.

FONTE: Google (2016), adaptado pelos autores do artigo. 
pescadores, oferecendo elementos biográficos, cotidianos, bem como percepções de transformações nas atividades de pesca, além de aspectos relativos a condições de saúde e doença. Pequenos trechos dos relatos recolhidos entremeiam as apresentações e são exemplos de manifestações próprias dos investigados, mostrando, para além de conteúdos, alguns padrões de suas comunicações.

\subsection{Perfis em retratos identitários}

Os três participantes da pesquisa pertenciam ao segmento mais pobre da população (classes socioeconômicas D-E [Associação Brasileira de Empresas de Pesquisa, 2016]). A atividade de pesca artesanal era o principal meio de suas subsistências. Eles apresentavam pouca escolaridade, não tendo chegado a concluir o ensino fundamental. Pedro relatou ter estudado até a $6{ }^{\mathrm{a}}$ série, Thiago era analfabeto e Tomé havia feito apenas o "primeiro ano primário". Os três pescadores referiram ter aprendido e começado a pescar ainda crianças: Pedro e Thiago, desde os dez anos, e Tomé, desde os oito anos. O conhecimento dessa atividade havia sido passado por familiares (tios e avós).

Tomé, um dos pescadores investigados, morava havia 35 anos em uma comunidade no município de Guarujá (SP). Estava com 70 anos na época do levantamento de dados; era casado, tinha sete filhos e sete irmãos; disse ter religião evangélica. Era magro, cabelo preto (sem nenhum aparente fio branco) e, assim como os dois outros participantes da pesquisa, possuía pele avermelhada, provavelmente devido à exposição ao sol. Apresentava-se sempre com camisa, calça social e calçando chinelos. Ele referia haver uma clientela cativa para a venda de seu pescado, nos arredores do local de sua moradia. Após pescar e fazer a limpeza do pescado, ele caminhava entre os becos da comunidade, indo de casa em casa para entregar os pedidos. Seu pai havia sido pescador, mas ele apreendera a pescar com seu avô. Um de seus filhos era pescador, e os outros filhos e a esposa também o ajudavam na pescaria. Tomé vivia numa casa de seis cômodos que, em outros tempos, possuía um quintal com algumas árvores e plantas frutíferas (como acerola, ameixa, coqueiro e abacateiro). Na época da pesquisa, restava um pequeno espaço desse terreno de plantação. Nele havia um pé de cajá-manga, algumas árvores de pequeno porte e alguma criação de patos e galinhas. Assim como outros moradores do bairro, ele cortou grande parte da vegetação de seu terreno para ampliar sua casa, de forma que dois de seus filhos também pudessem morar ali. Sua canoa, que levava o nome de seu filho mais velho, era pintada de amarelo e azul e podia comportar até três pessoas (“...é pequena... de seis metros"). Tomé trabalhava entre oito e dez horas por dia; dizia que tirava férias uma vez ao ano, "para visitar familiares no Norte (do país)". Ele costumava sair para pescar às seis horas da manhã, retornava com o sol a pino, almoçava, descansava, limpava o peixe ("....de cada dez por cento, aproveita um por cento...") [rendimento da limpeza do pescado], e saía para comerciá-los.

Buscando uma venda mais rendosa, Tomé limpava o peixe e retirava suas vísceras, referindo que, se o pescado fosse vendido diretamente para o 'peixeiro', o valor seria muito menor:

Sabe como que é vendido aquele bagre se eu for vender lá pro peixeiro? ...é um real o quilo... então eu faço filé do bagre... que eu vendo... eu vendo a dez reais o quilo do bagre... quer dizer, que estou aproveitando 
mais... eu estou tendo mão de obra... na faca (Tomé).

Pedro, outro pescador investigado, fazia alguns serviços de pedreiro, mas tinha na pesca de marisco sua principal fonte de recursos financeiros. Durante a pesca e a venda do pescado, trajava sempre uma bermuda e chinelos, sem camisa. Na época da pesquisa, estava com 50 anos, era casado, tinha três filhos e quatro irmãs. Somente sua filha mais nova ainda morava com ele e a esposa. Seu pai também foi pedreiro e seu tio foi quem o ensinou a pescar. Pedro morava em casa própria num bairro, no município de Guarujá (SP); residia ali desde que nasceu. Ele tinha dois barcos e um pequeno caminhão para transportá-los. Com a ajuda de mais dois pescadores (um deles, seu sobrinho), seu cotidiano no trabalho de pesca de marisco incluía mergulhar, com snorkel e pé de pato, próximo a um costão rochoso; usava uma espátula para retirar os mariscos, colocando-os num puçá (uma peneira em formato de coador). Ele subia à tona algum tempo depois de mergulhar e repetia o procedimento até que, após vários mergulhos, o puçá estivesse cheio. Apesar de obeso, Pedro mostrava ter flexibilidade e prática, descendo e subindo com os mariscos, mesmo em mar agitado. Por volta das seis horas da manhã, ele saía com seu barco a motor, levando os dois ajudantes; enquanto Pedro mergulhava, um deles ficava manejando os dois remos, para que o barco não mexesse muito com o movimento do mar. O outro ajudante recolhia o puçá, que de tempos em tempos era trazido cheio de mariscos. O retorno da pescaria ocorria por volta das dez horas da manhã, e em seguida era feita a limpeza e a venda do produto. Pedro também referiu ter clientela cativa, mas em bares e restaurantes da região.

Embora manifestando traços de temperamento alegre e brincalhão, Pedro mostrou inquietações ao relatar uma doença (tuberculose) que quase o levou à morte (“...devido à água suja, a água muito gelada, né?... eu não gosto de falar isso aí que se não eu choro, meu..."); ele ficou um ano sem trabalhar na pesca.

O terceiro pescador, Thiago, tinha 80 anos quando houve o levantamento dos dados; não tinha dentes nem dentadura, era magro e tinha a pele enrugada e com algumas manchas; sempre estava usando boné nos encontros da pesquisa. Disse ser analfabeto, mas conseguia assinar seu nome. Morava na Ilha Diana (Santos-SP) há 48 anos; antes disso, residia em outra ilha, mas havia se mudado após falecimentos em sua família.

No momento da pesquisa, a casa de Thiago estava sendo reformada para ampliação; muitas paredes estavam na alvenaria, com os blocos de concreto aparentes, sem reboco. Thiago disse ter sete filhos. Ele tinha sido criado por seu tio, que o ensinou a pescar, e de quem falava com bastante frequência. Referiu ter tido pouco contato com seu pai ("...vim conhecer meu pai com vinte e dois anos de idade, e meu pai já era segundo tenente de marinha, expedicionário... participou da guerra de quarenta...”). Thiago já estava aposentado, mas continuava a pescar. Disse que amava a pescaria (“... eu amo a pesca, eu amo o mar..., é minhas raízes, não tem jeito..."). Mostrava vitalidade, executando todo serviço relativo à sua pesca. Disse nunca ter bebido ou fumado, e criticou companheiros de pesca por fazerem excessivo uso de álcool e tabaco. Em um dos encontros, consertava o motor do seu barco, em outro, a bicicleta do seu neto. Muito sorridente e receptivo às atividades da pesquisa, sempre pareceu contente e valorizado com a experiência; referiu que já havia sido entrevistado pela imprensa local, 
e mostrava se orgulhar disso. Relatou que o que mais lhe dava orgulho (no sentido de honra e valorização) era o tempo de pescaria registrado em sua "carteirinha" ("...sou pescador, sou profissional... registrei minha carteira no porto com 16 anos...”). Segundo ele, dificilmente seria encontrado um pescador tão "velho de carteirinha". Parecia ser muito respeitado em seu bairro. Nas horas vagas, dormia, assistia TV e visitava a filha. Era devoto de Nossa Senhora de Monte Serrat (padroeira da cidade de Santos); relatou que rezava todos os dias, antes e após a pescaria, levando sempre um terço consigo. Thiago havia confeccionado sua canoa, mas não fazia mais seus apetrechos de pesca ("....tenho minhas embarcaçãozinhas... eu mesmo fiz a minha "chatinha" pra trabalhar... eu fazia rede, tarrafa, fazia tudo... agora a gente compra feito, né?"').

Thiago comentou sobre várias técnicas artesanais de pescado

Tudo foi pesca artesanal que eu conheço, mas no mar aberto não... artesanais, conheço todos, apetrechos eu conheço todos... isca de rede, tarrafa, ...que antigamente era caniço que agora é vara, mas antigamente era caniço... rede de espera, cerco, fiz muito cerco.

A técnica de "cerco fixo" era muito comum no complexo estuarino da Baixada Santista (Stori, 2010) e foi constantemente relatada nas entrevistas com os três pescadores caiçaras. Esse tipo de técnica é tido como um método sustentável de pescaria, pois permite a sobrevivência de organismos que não serão comercializados, por seu retorno pouco lucrativo ou mesmo pelo tamanho do pescado, devolvendo-os ao mar, ainda vivos. Entretanto, esse pescador relatou a impossibilidade de seguir com a pesca do cerco fixo devido às restrições legais (“... pescava camarão de dia à noite, trabalhava no cerco, eu gostava muito, gostava e gosto, só que agora não posso porque a lei que não permite que tire umas varas para fazer um cerco, correto?...”).

\subsection{Problemas referidos}

Os três pescadores investigados relataram declínio da pesca e escassez de pescado nos anos recentes, atribuindo como causas para isso a pesca predatória, a poluição, o movimento das embarcações no estuário santista e também as áreas de proibição ou impedimento para a pesca, como as militares, de proteção ambiental e as de terminais portuários.

É que nem eu lhe digo... o pescador sai cedo quatro horas da manhã ele está saindo pra pescar está perdendo o seu sono e não tem proveito... aí chega lá não tem produção e outra, muitas vezes não tem nem preço, é que hoje a situação está tão difícil pro lado do pescador que não tem nem preço (Tomé).

Dois dos três pescadores avaliaram ser o grau de risco de seu ofício/profissão como grave (em respostas a perguntas específicas sobre o grau de risco). O mar agitado, as intempéries do tempo e o perigo de afogamento foram alguns dos motivos descritos para este risco. Também referiram problemas de saúde. Tomé disse ter colesterol alto e labirintite e Pedro falou que quase morrera de tuberculose, associando-a à atividade da pesca.

Segundo Tomé, “...na pescaria você fica muito tempo no mar. Se você está doente não vai voltar para casa... Tem todo esse detalhe essa dificuldade, como eu já falei pra você, levando chuva, levando sereno, levando friagem...".

Me molhei todinho, todinho, meu Deus do céu! O 
tempo frio, quando eu cheguei aqui em frente à baía, já estava de noite, um vento gelado, eu todo molhado, rapaz... perdi tudo, um dia de trabalho, perdi tudo... Quase que morri afogado, perdi tudo... perdi rede, perdi mercadoria, perdi até as botas... perdi tudo, rapaz (Thiago).

E voltando um pouquinho atrás, em dois mil e cinco tive doente, trabalhei, é... fiquei um ano parado, da pesca, tive tuberculose. Devido à água suja, a água muito gelada, né... então a gente ficava muito tempo na água, peguei um, uma bronquite, como é, umas, umas tosses, começou a dar tosse, deu pneumonia, daqui a pouco deu... por causa da tuberculose... fiquei... a primeira vez fiquei sete dias internado, depois fiquei vinte e sete dias (Pedro).

Todos os participantes indicaram não usar equipamentos de proteção individual (EPIs). Tomé relatou que usava luvas e filtro solar, práticas que não foram observadas em nenhum dos cinco encontros com ele. Pedro dizia usar roupa de mergulho, mas isso também não foi observado nos quatro encontros com ele. Seus ajudantes, da mesma forma, não utilizavam nenhum EPI. Geralmente iam pescar apenas de bermuda, sem camiseta e calçando chinelos.

Os três investigados não referiram problemas de distúrbio de uso do álcool (em avaliação com instrumental específico - AUDIT) e nenhum deles declarou usar drogas.

\subsection{Riscos, medos e inseguranças}

A pesca artesanal do marisco pode ser muito arriscada. Nos encontros com Pedro, puderam ser observadas condições de mar muito agitado, com ondas muito grandes e fortes vindo ao seu encontro, quando ele ficava no costão rochoso do qual retirava mariscos. Essas condições também são fonte de risco quando se decide mergulhar para a retirada do pescado, uma vez que o tempo para a coleta dos mariscos (estando o pescador submerso) aumenta. Os ventos e temporais foram tidos como os maiores perigos no mar.

No mar quando a gente pega temporal... o que nós mais têm medo do temporal é o vento, porque o mar quando engrossa ele não dá brecha pra ninguém e a gente passa apuros. Mas também os tempos de trovoada faz muito medo por causa dos raios, teve dia de eu ir mais o meu filho pescar no mar e eu falar pra ele não pegar em nada de ferro, não toca no motor, fica no cesto aí quietinho coberto com uma capa ali e se o vento está forte nós já volta vem embora porque não tem quem reaja com o vento, o vento não alisa. É o que faz mais medo ao pescador é o vento, se está lá fora bate um vento o pescador já está pensando de vim pra terra por causa do vento. E o mar quando engrossa não tem embarcação pra o mar, um barco daquele se torna uma cuiazinha dentro d'água, um navio que é grande ele balança, agora imagina um barco, então a gente também passa esses sustos esse medo, não existe aquele que assim: 'eu sou campeão do mar'... não tem, não existe... a gente faz tudo por onde trabalhar, mas não deve abusar porque a natureza é maior que a gente (Tomé).

\subsection{Antagonismos: pescador herói e trabalho precário}

Os três pescadores caiçaras investigados falavam com autoridade de assuntos relacionados à pesca, como um universo que eles pareciam dominar. Os enaltecimentos à ocupação incluíam atributos de conhecimentos peculiares, de força física, de resistência às intempéries e enfrentamento de muitos 
riscos. Pedro afirmou: "Eu era um monstro trabalhando, um monstro...”. Em Thiago, encontrou-se:

Aqui dentro ninguém pesca como eu pesco [...] não é pra qualquer um mesmo... tem colega que fala: 'Pô T., você tem muito filho' [...] tenho sete filhos, e falei assim pra ele: criei tudo assim em cima dessa água aqui abençoada por Deus ... 'puxa vida você é um herói, hein.!'... falei, não, é a minha profissão.

Tomé disse: “... é feito na mão mesmo, se tá vendo aqui, que é feito na mão ...não é nada de fábrica não... é na mão, é na raça.”

Ao lado dessa característica de enaltecimento da profissão, numa identificação do pescador como um herói que enfrenta as adversidades, os investigados também indicaram a identificação de pescador como um trabalhador sofredor, que passa por muitas dificuldades ao longo da vida para ter o sustento da família. Pedro disse: "é... de mim, de mim é... eu tenho a vida meia, meia, meia ruinzinha... minha vida foi sofrida". Em Thiago também se encontrou a referência ao sofrimento:

Pra viver só de pesca precisa ter coragem... tempo ruim, mosquito, mosquito aquele mais miudinho... dá pra você pescar, você ganhar um dinheirinho até, mas dá uma semana, na outra tu não faz nada, às vezes passa duas, três semana que tu não faz nada, então é... é embaçado, né? ... eu sou uma pessoa sofrida.

De forma semelhante, Tomé também afirma:

Muito trabalho, muita luta, muita dificuldade, mas isso é... faz parte do dia a dia... porque, o pescador você sabe, ele sofre de qualquer maneira... o pescador batalha, o pescador... ele sente frio, ele sofre na friagem no tempo do inverno... tempo da chuva, ele sofre na chuva, levando chuva... levando sol, comendo fora de hora.... a vida de pescador é vida sofrida viu, não é brincadeira.

Dessa forma, os investigados pareciam se identificar dentro de fronteiras do binômio "pescador artesanal como uma profissão de sofredores" $\mathrm{X}$ "pescador artesanal como um ofício gratificante e honroso". No primeiro elemento do binômio estavam as características de uma profissão com doses de desqualificação, e no segundo elemento, um ofício repleto de qualidades, especialmente pela intimidade com o mar. Ainda quanto a aspectos mais qualificados, a pesca artesanal seria uma forma não danosa ao meio ambiente, no qual o homem subtrai da natureza o essencial para a subsistência de sua família, sem comprometer o ciclo natural da vida, inserindo-se nesse ciclo.

\section{Discussão}

Os resultados expostos serão a seguir discutidos numa perspectiva mais ampla, indo-se dos retratos anteriores a uma "fotografia de paisagem" composta principalmente por contribuições de Adams (2000a), Little (2002) e Castro (2006). Todos são representantes de produção científica acerca do tema controverso da definição de populações tradicionais. Também, nessa discussão, são conjuntamente apresentados pequenos trechos dos relatos recolhidos dos três pescadores investigados, numa tentativa de articular a dimensão psicossocial fruto do investimento empírico à discussão teórico-conceitual sobre populações tradicionais, travada especialmente nos campos das ciências sociais e naturais.

O trabalho de Adams (2000a) trata da questão 
da formação, na primeira metade do século $\mathrm{XX}$, das comunidades de pescadores, destacando particularmente sua passagem da lavoura como atividade principal à pesca. Adams, com esse movimento, implicitamente questiona o caráter tradicional dessas comunidades, dada a suposta juventude de sua inserção marítima.

$\mathrm{O}$ argumento em que Adams (2000a) busca se apoiar mais fortemente para encontrar uma espécie de lacuna nesse debate é o que associa o tradicional à transmissão de conhecimentos através das gerações. Deve-se ressaltar que a autora avalia que a formação de uma tradição parece não combinar com algo como "duas gerações", como em muitos casos de comunidades caiçaras. Algo que data da década de 1930, a organização dessas comunidades em torno da pesca e, sobretudo, como muitos estudiosos enfatizam, as transformações da atrativa inserção do motor aos barcos podem ser fenômenos retratados como algo muito recente. A seu turno, os pescadores demonstraram, durante as entrevistas, saber tácito (típico de relações tradicionais) do meio ambiente, apresentando um "saber fazer" e uma adaptabilidade que o indivíduo que habita exclusivamente os centros mais urbanizados não parece possuir. Há relatos claros disso:

Então, um, um... uns dez anos pra cá mudou muito né, a pescaria diminuiu muito... então, aí... você tem que começar a pegar, porque você tem filho, você tem neto, você tem... várias coisas né, pra trabalhar... então você tem que começar a dar umas modificadas na pescaria, mas a pescaria é em primeiro lugar porque ela é o nosso... ela é o que a gente sabe fazer (Pedro, grifo dos autores).

A gente em casa também, às vezes, muita da vez também se adapta a criar uma criação, tem aí, a gente aí tem a criação de pato, galinha... tem a criação também. Mas de ser só pescador não tem criação, tem. Isso nós que mora aqui na cidade, mas quando nós somos pescador que nós moramos, vamo dize, num lugar mais interior, nós planta também uma roça pra te um fruto da roça... em casa também faz isso. O meu avô foi pescador, a gente também desfrutava de fruto da roça, sempre tinha um feijão, tinha um milho, tem o arroz, uma melancia, uma abóbora, sempre tinha um fruto da terra pra ajudar... criava também umas criações de cabrito pra te leite, isso é muito bom... já aqui na cidade, a gente não tem espaço pra isso (Tomé).

Adams (2000a), em suma, parece à primeira vista buscar redesenhar a figura do pescador caiçara nos seus trabalhos, mas, na prática, mais uma vez confirma o que parte destacada da literatura sobre populações tradicionais defende (além de Little e Castro, mais explorados a seguir, vale enfatizar aqui a importância de Diegues [1999, 2000] nesse ponto): os pescadores artesanais em que se foca aqui são, antes de mais nada, herdeiros do caipira paulista, cujas ligações com o mundo tradicional pressionado pelas transformações diversas não podem ser negligenciadas, e, nesse sentido, estão intimamente ligados a populações cujos traços fortes são suas relações com a terra, o lugar, e simultaneamente com uma dada cultura e práticas de interação com o meio ambiente. Como afirma Little (2002, p. 23),

O uso do conceito de povos tradicionais procura oferecer um mecanismo analítico capaz de juntar fatores como a existência de regimes de propriedade comum, o sentido de pertencimento a um lugar, a procura de autonomia cultural e práticas adaptativas sustentáveis que os variados grupos sociais analisados aqui mostram na atualidade.

A avaliação do autor enfatiza a semelhança, mas reconhecendo a diversidade - e aqui, vale dizer, diversidade inclusive em relação aos traços 
fortes e centrais dos diversos perfis de populações tradicionais, que é, em geral, sua relação com a terra (ou o ambiente). Sem dúvida, o grau de interação das populações tradicionais com a sociedade urbano-industrial contemporânea varia em uma escala bastante ampla. O dégradé vai de indígenas amazônicos isolados até populações absolutamente integradas e com uso massivo de tecnologias contemporâneas. Nessa perspectiva, é possível encontrar entre os pescadores pesquisados falas que denotam seu grau de integração como algo intermediário, aparecendo temas como comércio, técnicas ou tecnologias e dinheiro:

Então a gente tirava aqui... latas de mariscos, ...era trinta, quarenta latas de marisco... todo mundo comprava. Depois que inventaram aquele negócio do marisco de cativeiro, cabô, cabô, cabô a pescaria... então, acabou mais a nossa, nossa...a nossa produção diminuiu muito né, e o marisco também já diminuiu muito também né... lá se ganhava dinheiro né... quem era pescador aqui já chegou a comprar casa, pô, trabalhando com marisco (Pedro).

Falei pra você, vou repetir de novo, desde da estaquiada até o cerco eu conheço tudo da pescaria, faço rede, faço tarrafa, faço carapuça, faço puçá... faço tudo isso aí... Inclusive quando eu fiz aquela coisa [comercial para a TV] pra aquela firma lá...Embraport [Empresa Brasileira de Terminais Portuários]...eu tive que pegar uma rede e reemendar, os cara filmaram eu remendando a rede, eu tive de fazer tudo isso aí... mas eu fiz e os cara gostaram pra caramba (Thiago).

Castro (2006) afirma, em um texto que pode ser considerado seminal sobre esse tema, algo comparável às colocações de Little acerca da diversidade de povos que devem ser considerados como tradicionais. $\mathrm{O}$ antropólogo unifica coletivos como caiçaras, caboclos, camponeses e indígenas por meio da figura do próprio indígena, já que dentro do caldeirão de misturas genéticas ele prefere olhar para os cruzamentos da história que ligam tais coletivos e não para supostos momentos ou "estados puros". Para Castro (2006, s/p):

Por mais bem-sucedido que tenha sido ou esteja sendo o processo de desindianização levado a cabo pela catequização, pela missionarização, pela modernização, pela cidadanização, não dá para zerar a história e suprimir toda a memória, porque os coletivos humanos existem crucial e eminentemente no momento de sua reprodução, na passagem intergeracional daquele modo relacional que 'é' o coletivo, e a menos que essas comunidades sejam fisicamente exterminadas, expatriadas, deportadas, é muito difícil destruí-las totalmente.

Há dois temas que surgem com força nos excertos de Little (2002) e Castro (2006), que são o da ligação com a terra e o da memória. É possível, para ambos os casos, destacar trechos das falas dos pescadores com esses temas sendo abordados a partir de uma perspectiva que reforça seu caráter tradicional dentro dessa concepção mais ampla em que, por exemplo, a terra ou o lugar de origem (aquela terra e aquele lugar precisamente) promovem laços e despertam lembranças e afetos:

Eu gosto de viver assim, agora... dizer que vivo só da pesca, não vou dizer pra você que vivo só da pesca porque não dá mais mesmo... ali aonde é a Embraport, eu já falei pra você da outra vez, ali era um pesqueiro muito bom pra gente [...] agora tem o cais, não posso nem chegar lá, né? Nem passar perto não posso, porque segurança vai lá e fala: e aí? Antigamente não... chegava lá, encostava em terra e tal, tal... batia papo com os colegas e tal... e pegava um siri de gancho lá na costeira... era bom pegar siri gancho [...] Então rapaz, então assim... eu tenho às vezes saudade porque 
me criei ali, né, hoje eu não posso ir lá... é da Embraport, é da Embraport eu não posso ir lá, se eu for entrar no mato lá, pra olhar qualquer coisa, pensam que eu vou roubar, aí já não dá, né? Então não dá, e eu sinto saudade, já pesquei pra aquelas cabeceiras de rio lá, rapaz, pegar caranguejo, tinha tudo sítio de bananeira, sabe?, ... porque as estrada, eles aterram uma parte, abre o canal na outra... vai cortando o sistema das marés, nos rios... isso estraga pra caramba, sabe? Eu lembro que nem aqui na Embraport... antes da Embraport vim pra cá eles cortaram o rio dali pra lá... é um furado que se chama... o rio o outro de lá, morreu, entupiu... ficou aquela parte dali pra cima só (Thiago).

Essas duas leituras, de Little (2002) e Castro (2006) são, sem dúvida, formas diferentes daquela defendida por Adams (2000a), por exemplo, de entender a questão da tradição, da relação com o ambiente e da transmissão de valores e práticas, já que não se busca medir algo tão complexo a partir de uma dimensão temporal.

Ao final do processo, destaca-se nos retratos psicossociais de pescadores caiçaras aqui traçados a presença de elementos dessa relação diferenciada com o ambiente em comparação a uma cultura mais fortemente urbana, sublinhando-se especialmente a glorificação de seu ofício em meio às dificuldades impostas pelo ambiente marítimo.

De forma mais ampla, é possível considerar o potencial de cobertura analítica e ação política do conceito de "tradicional", a despeito das diferenças entre os grupos mencionados na literatura. Afinal, não é pouco o que está em jogo com a mobilização da noção polêmica de população tradicional. Pode-se, com isso, demarcar identidades, fronteiras, tais como as que se pôde ver aqui por meio dos retratos apresentados. Tal demarcação identitária pode resultar na direção de sua eliminação ou na de sua valorização, com a garantia do espaço para a existência da diferença em meio ao predomínio do modelo de desenvolvimento socioeconômico urbano, industrial e altamente tecnológico.

\section{Considerações finais}

Buscou-se, neste trabalho, investigar aspectos identitários de três pescadores artesanais da Baixada Santista, traçando retratos psicossociais. Por fim, a proposta foi de buscar articular esses retratos a um panorama mais amplo de discussão sobre a definição das chamadas "populações tradicionais".

Como limites do trabalho, é possível sublinhar que se tratou de uma abordagem qualitativa com três entrevistados que merece ampliação em próximos estudos, e que a discussão sobre a controvérsia envolvendo a definição de populações tradicionais não pôde ser aprofundada neste espaço, pretendendo-se apenas esboçar linhas de força e diferenças entre duas abordagens bastante frequentes na literatura. A primeira delas, frequentemente mais voltada a estudos de conservação dos ecossistemas e que tende a questionar a sustentabilidade das práticas de manejo das populações ditas tradicionais, tem tido mais representantes no campo da ecologia, e a outra, normalmente direcionada à defesa de populações e coletivos minoritários do ponto de vista sociocultural, tem sido mais defendida no campo das ciências sociais, o que traz como desafio fazer com que novas pesquisas empíricas busquem elucidar essa controvérsia nutrida entre áreas diferentes do saber, e quem sabe na trilha de uma aprofundada abordagem interdisciplinar. 


\section{Agradecimentos}

Agradecimentos especiais aos pescadores artesanais entrevistados, à especialista em geoprocessamento, Loretha Almeida do Nascimento, e à Fernanda Ribeiro de Araújo, do Laboratório de Psicologia Ambiental e Desenvolvimento Humano (LADH/UNIFESP-BS).

\section{Referências}

Adams, C. As populações caiçaras e o mito do bom selvagem: a necessidade de uma nova abordagem interdisciplinar. Revista de Antropologia, 43(1), 145-182, 2000a. doi: 10.1590/S0034-77012000000100005

Adams, C. As roças e o manejo da Mata Atlântica pelos caiçaras: uma revisão. Interciência, 25(3), 143-150, 2000 b.

Adams, C. Identidade Caiçara: exclusão histórica e sócio-ambiental. In: Albuquerque, U. P. de; Alves, A. G. C.; Silva, A. C. B. L. E; Silva, V. A. da (Orgs.). Atualidades em Etnobiologia e Etnoecologia: Palestras convidadas. Recife: Sociedade Brasileira de Etnobiologia e Etnoecologia, 2002.

Associação Brasileira de Empresas de Pesquisa. Critério de Classificação Econômica Brasil. São Paulo, 2016.

Bardin, L. Análise de conteúdo. Lisboa: Lisboa Edições, 70. ed., 2009.

Bezerra, S. M. de F. M. de C.; Sotto, M. N.; Orii, N. M.; Alves, C.; Duarte, A. J. da D. S. Efeitos da radiação solar crônica e prolongada sobre o sistema imunológico de pescadores do Recife. Anais Brasileiros de Dermatologia, 86(2), 222-233, 2011. doi: 10.1590/S0365-05962011000200004

Brasil. Decreto $n^{\circ} 3.048$, de 6 de maio de 1999. Aprova o Regulamento da Previdência Social, e dá outras providências. Brasília: DOU de 07/05/1999.

Brasil, S. S. Trabalho, adoecimento e saúde: aspectos sociais da pesca artesanal no Pará. Belém, Dissertação (Mestrado em Ciências Sociais-Sociologia) - UFPA, 2009.
Castro, E. V. de. No Brasil, todo mundo é índio, exceto quem não é. Entrevista concedida à ISA-SP, 2006.

Diegues, A. C. S. Diversidade biológica e culturas tradicionais litorâneas: o caso das comunidades caiçaras. In: Conferencia da União Internacional para Conservação da Natureza e dos Recursos Naturais, São José-Costa Rica, 1988.

Diegues, A. C. S. A sócio-antropologia das comunidades de pescadores marítimos no Brasil. Etnográfica, 3(2), 361375,1999 .

Diegues, A. C. S. (Org.). Os saberes tradicionais e a biodiversidade no Brasil. São Paulo: Ministério do Meio Ambiente, dos Recursos Hídricos e da Amazônia Legal, 2000.

Di Felice, M.; Torres, J. C.; Yanaze, L. K. H. (Orgs). Redes digitais e sustentabilidade: as interações com o meio ambiente na era da informação. São Paulo: Annablume, 2012.

Erikson, E. H. O ciclo de vida completo. Porto Alegre: Artmed, 1998.

Freitas, R. R. de; Seixas, S. R. da C. A pesca artesanal frente às instituições sociais modernas e os desafios do desenvolvimento territorial. Revista Vitas-Visões Transdisciplinares sobre Ambiente e Sociedade, 1, 2011.

Lira, F. F. M. Entre artifice e operário: discursos sobre o trabalho do pescador artesanal. Fortaleza, Dissertação (Mestrado em Psicologia) - UNIFOR, 2010.

Little, P. E. Territórios sociais e povos tradicionais no Brasil: por uma antropologia da territorialidade. Série Antropologia, 322, 2002.

Moreira, W. Considerações sobre a cadeia produtiva do pescado artesanal na Baixada Santista/SP. Cadernos CERU, 21(1), 89-111, 2010.

Moreira, W.; Castro, P. M. G. de; Menezes L. C. B. de. A Explotação dos Manguezais da Baixada Santista-SP, através da Memória das Comunidades Locais. In: VI Congresso de Meio Ambiente da Associação de Universidades Grupo de Montevidéu, Montevidéu, 2009.

Nagib, V. Os impactos da dragagem de aprofundamento do canal de navegação, bacias de evolução e berços de atracação do Porto Organizado de Santos (SP) nas co- 
munidades caiçaras da área de influência do projeto. São Paulo, Monografia (Pós-Graduação Lato Sensu em Meio Ambiente, Desenvolvimento Sustentável e Questões Globais) - FAAP, 2014.

Noffs, P. As mudanças sociais e a cultura caiçara. In: Seminário: a cultura caiçara e suas transformações, NUPAUB/ SESC, 2006.

Pena, P. G. L.; Martins, V.; Rego R. F. Por uma política para a saúde do trabalhador não assalariado: o caso dos pescadores artesanais e das marisqueiras. RBSO, 38(127), 57-68, 2013. doi: 10.1590/S0303-76572013000100009

Rios, A. de O.; Rego, R. de C. F.; Pena, P. G. L. Doenças em trabalhadores da pesca. Revista Baiana de Saúde Pública, 35(1), 175-188, 2014.

Rocha, D. F. Impactos da exploração petrolifera sobre a pesca, os ecossistemas costeiros e a situação de saúde de comunidades de pescadores artesanais de Macaé/RJ. Rio de Janeiro, Dissertação (Mestrado em Ciências) - FIOCRUZ, 2013.

Rodrigues, A. M. Operário, operária: Estudo exploratório sobre o operariado da Grande São Paulo. São Paulo: Símbolo, 1978.

Romani, C. O discurso cultural e ambientalista das comunidades de pescadores caiçaras na luta pela terra: uma análise histórica do conflito ambiental no canal de Bertioga, na Baixada Santista. História Oral, 2(14), 31-62, 2011.
Rosa, M. F. M.; Mattos U. A. de O. Trabalho \& Saúde: a vulnerabilidade dos pescadores da Baía de Guanabara. In: Anais do $1^{\circ}$ Seminário de Sociologia da Saúde e Ecologia Humana. Florianópolis: UFSC, 2010.

Santos, W. S. dos; Gouveia; V. V., Fernandes, D. P.; Souza, S. S. B. de; Grangeiro, A. S. de M. Alcohol Use Disorder Identification Test (AUDIT): explorando seus parâmetros psicométricos. Jornal Brasileiro de Psiquiatria, 61(3), 117-123, 2012. doi: 10.1590/S0047-20852012000300001

Silva, A. X. S. Ambiente pesqueiro e saúde: representações sociais sobre saúde e doença de pescadores e marisqueiras nos distritos de Diogo Lopes, Barreiras e Sertãozinho Macau RN. Natal, Dissertação (Mestrado em Ciências Sociais) - UFRGN, 2013.

Stori, F. T. Adaptatividade e resiliência no sistema socioecológico da comunidade caiçara da Ilha Diana, município de Santos-SP. São Carlos, Tese (Doutorado em Ecologia e Recursos Naturais) - UFSC, 2010.

Stori, F. T.; Nordi N.; Abessa D. M. de S. Mecanismos socioecológicos e práticas tradicionais de pesca na comunidade caiçara da Ilha Diana (Santos, Brasil) e suas transformações. Revista de Gestão Costeira Integrada, 12(4), 521-533, 2012. doi: $10.5894 /$ rgci355

Vale, M. Pesca artesanal na Ilha Diana e meio ambiente: Um estudo de caso. Revbea, 6, 71-75, 2011. 